\title{
The Certainty, Modality, and Grounding of Newton's Laws
}

\author{
Zvi Biener and Eric Schliesser \\ Forthcoming in The Monist \\ Special issue on "Laws of Nature," edited by \\ Angela Breitenbach and Michela Massimi
}

\begin{abstract}
Newton began his Principia with three Axiomata sive Leges Motus. We offer an interpretation of Newton's dual label and investigate two tensions inherent in his account of laws. The first arises from the juxtaposition of Newton's confidence in the certainty of his laws and his commitment to their variability and contingency. The second arises because Newton ascribes fundamental status to both the laws and to the bodies and forces they govern. We argue the first is resolvable, but the second is not. However, the second tension shows that Newton conceives laws as formal causes of bodies and forces. This neo-Aristotelian conception goes missing in Kantian accounts of laws, as well as accounts that stress laws's grounding in powers and capacities.
\end{abstract}

\section{Introduction}

Newton began his Principia with three now-famous "laws of motion." He also called these "axioms," a fact that is often forgotten. It is not obvious why he used both terms. In this paper, we offer an interpretation of Newton's dual label, Axiomata sive leges motus (Axioms or Laws of Motion). We claim that by using the terms Newton signals that his foundational principles can be understood as certain premises, shared with the broader natural philosophical community of his time.

We are not the first to note this. George Smith (2014) has proposed to treat the laws as deeply entrenched working assumptions, while Kantian accounts like Michael Friedman's (2001, 2009) have treated the laws as constitutive principles. To shed light on both sorts of claims, we investigate two tensions inherent in Newton's account of laws. The first arises from the juxtaposition of Newton's confidence in the certainty of the laws and his commitment to their variability and contingency. The second arises because Newton ascribes fundamental status to both the laws of nature and to the bodies and forces they govern. We argue that the first tension is resolvable, while the second is not. However, the second tension shows that Newton conceives the laws of nature as formal causes of the bodies and forces which they govern and in which they are grounded. We argue that this neo-Aristotelian conception goes missing in Kantian accounts of Newton's laws, as well as accounts that stress laws's grounding in powers and capacities.

To show this, we draw on the pre-history of Newton's treatment of 'laws' in the drafts leading to the Principia (\$2). We show that Newton introduced "Axiomata sive Leges Motus" as he grew confident in the certainty of his laws and the fact that they underlay all previous 
mechanical practice. Newton's confidence in the certainty of his laws gives rise to the first tension described above. In $\S 3$, we discuss this tension, as well as Newton various statements concerning the modality and grounding of the laws. We conclude that Newton understands laws on the model of formal causation. We close the paper by comparing this conception of laws to several contemporary accounts.

\section{2. 'Axiomata sive Leges Motus' as Shared, True Premises}

To determine the meaning of "axioms" and "laws" for Newton, it is instructive to uncover the considerations that prompted their use in the Principia. ${ }^{1}$ The Principia was the result of a series of increasingly sophisticated works known as the De motu drafts, initially aimed at determining the shape of planetary orbits, supposing an inverse-square attraction towards the sun. ${ }^{2}$ Strikingly, while the Principia began with three Axiomata sive Leges Motus, the initial De motu drafts only began with a series of hypotheses ("Hyp" or "Hypoth"). Newton's decision to switch terminology is our concern here. ${ }^{3}$

The use of "hypotheses" in physico-mathematical tracts was common in Newton's time. For example, the deductive portion of Christiaan Huygens's Horologium Oscillatorium (1673)a work Newton admired-began with three "hypotheses." Huygens employed the term for principled reasons. He believed that the best we could achieve in natural philosophy was an explanatory intelligibility founded on conjecture and the mechanical principles of shape, size, and motion. Empirical evidence could rule out certain conjectures and give others a high degree of probability, but natural philosophical truth was beyond human ken (Huygens 1690, 125). Newton did not agree that natural philosophy was confined to hypothetical reasoning, but neither was he ready to claim in his first tract-De motu corporum in gyrum - that his initial premises were certain or even particularly important. ${ }^{4}$ At this stage of composition, Newton was merely answering a mathematically challenging and astronomically noteworthy question brought to him by Edmond Halley, but was yet to realize that its solution entailed a reconceptualization of the basic principles of natural philosophy. ${ }^{5}$

"Hypotheses" also began the following version of the tract-De motu corporum in fluidis. They included forerunners to the first two laws, as well as theses concerning resistance, the relativity of motion, and the idea that "By the mutual actions between bodies the common center of gravity does not change its state of motion or rest" (299). In this tract, Newton also engages more explicitly with questions of space, time, and cosmology, but cautiously. He notes that since we cannot determine from the motions of the planets whether the center of gravity of the solar system is moving, we may take it to be at rest and so "the Copernican system is proved a priori" (301). This is the first clear indication that Newton sees his tract as more than a

\footnotetext{
${ }^{1}$ All reference to the Principia are to Newton (1999).

${ }^{2}$ All references to De motu are to Herivel (1965).

${ }^{3}$ We can only rehearse part of the story. The evolution of Newton's thought in 1684-1685 is complex and involves some of the most significant conceptual leaps taken in the latter half of the seventeenth century. Newton himself did not see their full implications for decades (Biener, forthcoming-a).

${ }^{4}$ For Newton's anti-hypothetical stance of the 1670s, see Shapiro (1989). Newton's ardent refusal in the 1670 s to accept hypothetical reasoning makes clear that his use of "hypotheses" in 1684 is not unconsidered. Rather, it indicates that he did believe the worked passed the epistemic bar that turned "conjectures" into "certainties." See also Stein (1990).

${ }^{5}$ For the events that lead to the Principia's composition, see Cohen (1971, 47-54).
} 
mathematical exercise, but as answering the central question of seventeenth century natural philosophy. However, Newton also recognizes that since the center of the solar system is not identical with the sun, the planets "neither move exactly in ellipses nor twice in the same orbit." In what has been dubbed the 'Copernican Scholium,' the complexity of planetary orbits leads Newton to despair that:

[T]o consider simultaneously all these causes of motion and to define these motions by exact laws allowing of convenient calculation exceeds, unless I am mistaken, the force of the entire human intellect." (301, emphasis added)

At this point, Newton believes that we could not go beyond a rough description of "the system of the world." Echoing Descartes, he seems resigned to the idea that empirical complexity will make it impossible to gain detailed knowledge of real motions, their causes, and their laws. ${ }^{7}$

We come now to our focus. Sometime after writing the above hypotheses, Newton crossed out the word "Hypoth" and replaced it with "Lex." This is the first instance of "law" (as a heading) in the De motu composition sequence (Newton 1989, 13). Since the tract also concludes with the claim that laws lay beyond the reach of the human intellect, it is almost certain that the cross-out occurred after the tract was complete. Consequently, the reasons for Newton's introduction of "law" are likely connected to the developments made explicit in the subsequent tract, De motu in regulariter cedentibus.

In this tract-which begins with six "Leges Motus"-Newton suggests that his previous attitude was too pessimistic. He distinguishes absolute and relative quantities and begins to work out a method that can determine, at least in principle, "true" from "apparent" motions. ${ }^{8}$ The tract is striking in its recognition of the deep conceptual connections between Newton's laws of motion, particularly the third law, and previously accepted principles of mechanics, including the relativity of motion and the claim that the motions of bodies among themselves do not change the state of motion of their center of gravity. The distinction between absolute and relative quantities also shows that Newton began believing he could determine how motion really is, not merely how it appears to us. This is surely one of the reasons that led him to cross out 'hypotheses' and replace them with 'laws' in the very same tract where he previously wrote that to define motions by exact laws exceeds the force of the human intellect. In fact, the removal of the pessimistic Copernican Scholium suggests he came to believe he found a means of determining the system of the world despite the ineliminable complexity of planetary orbits and the ineliminable epistemic limits set by the relativity of motion. ${ }^{9}$

Moreover, it seems Newton came to believe that the principles that allowed him to describe the true world system were intertwined not just with astronomical tenets (like Kepler's 'area law'), but with the foundations of traditional terrestrial mechanics. ${ }^{10}$ Newton makes the

\footnotetext{
${ }^{6}$ See Section 2 of Smith (2007) for the wider significance of the so-called "Copernican Scholium."

${ }^{7}$ On the Cartesian despair of exact natural philosophy, see Garber (2000).

${ }^{8}$ For a discussion of the method, see Smith (2002). The distinction between absolute and relative quantities also suggests that Newton begins thinking about mechanics as tracking abstract quantities, a feature that will be constitutive of his work in the final Principia (see Smeenk and Schliesser 2013).

${ }^{9}$ We own this insight to George Smith, e.g., (2008).

${ }^{10}$ Of course, what counts as 'mechanics' is a fraught question. It is clear that the scope of 'mechanics' was different for different seventeenth-century authors. The field was only loosely defined by a set of (neither necessary nor sufficient) concerns. These included the use of mathematics, the distinction between natural and artificial construction; a broadly non-Aristotelian matter theory, the rejection of teleological explanation, etc. We thank an
} 
connection between his laws and the mechanical tradition explicit. In the same tract, after the first two laws, he writes that "By means of these two laws now widely acknowledged Galileo discovered that projectiles under a uniform gravity acting along parallel lines described parabolas ..." (312, emphasis added). Newton had not previously drawn the connection between his exercise in mathematical astronomy and terrestrial motion. Here, however, he asserts that his answer to Halley's question was based on principles that were endorsed by Galileo himself and "widely acknowledged" by the previous half century of research into projectile motion. ${ }^{11}$ Moreover, in a later development of the same passage, in the scholium to the laws of the Principia, Newton joins together the study of projectile motion and collision theory: "From the same laws..., Sir Christopher Wren, Dr. John Wallis, and Mr. Christiaan Huygens, easily the foremost geometers of the previous generations, independently found the rules of the collisions and reflections of hard bodies ..." (Principia, 424, emphasis added).

This scholium to the laws is worth commenting on. Its main task is to defend the laws' validity: it begins by asserting that "the principles I have set forth are accepted by mathematicians and confirmed by experiments of many kinds" (Principia, 424). Newton's mentions of Wren, Wallis, and Huygens in this context are no coincidence. In 1666-1668, the Royal Society held a highly publicized competition to determine the "Laws of Motion" (see Jalobeanu 2011). Wren, Wallis, and Huygens took part, and responded to the challenge with mathematically equivalent formulations. Each account, however, was based on different foundational principles and concepts, a fact of which Newton was well aware. ${ }^{12}$

On the face of it, it thus seems that Newton misrepresents the history of his own field, falsely suggesting that his laws were already agreed upon. Why? It seems to us that his appeal to the (invented) consensus of virtuosi of his time is meant to recruit their authority and the authority of their independent investigations, to show that his principles are not arbitrary hypotheses he had manufactured ad hoc. Of course, Newton was not being entirely disingenuous. As he shows in the scholium by recovering basic results regarding simple machines, pendulums, and collision, his principles were implicitly presupposed in previous mechanical works, even if not explicitly recognized. ${ }^{13}$ Newton's dual appeal to the authority of, and genuine confirmation through, previous mechanical research is clear in the scholium's first sentence: "the principles I have set forth are accepted by mathematicians and confirmed by experiments of many kinds" (Principia, 424). Importantly, Newton first made this appeal — initially only to Galileo - in the first De motu tract that fully replaced "hypotheses" with "laws;" this seems like no coincidence, although this must remain a matter of speculation.

anonymous referee for stressing this point. For further discussion, see Gabbey (1992), Bertoloni Meli (2006), and Kochiras (2013). We use 'mechanics' here to broadly denote the field of investigation concerned with projectile and pendular motion, as well as the five simple machines.

${ }^{11}$ Hall (1952)

${ }^{12}$ For the significance of this claim, see Schliesser (2011b). Newton himself wrote a tract titled "Lawes of Motion" in the 1660s. It is a work very much in the spirit of the Royal Society competition. It makes clear that Newton's decision not to begin the De motu drafts with "laws" and only adopt it later is significant. After all, he was not averse to the term and even used it himself in appropriate contexts.

${ }^{13}$ The project is further expanded in Section X of the published Principia, where Newton shows that he can exactly recover results that in the Galilean-Huygensian tradition were derived assuming a uniform, parallel gravity, but assuming his own laws and an inverse-square, centripetally directed gravity. See Smeenk and Smith (mss). 
Newton next authored two works titled De motu corporum, Liber Primus. The first use of "Axiomata" of which we are certain is in the second Liber Primus. ${ }^{14}$ In the early modern period, an axiom was often understood as an established principle, one that is widely, if not universally, accepted; e.g., "the whole is greater than a part" and (counterintuitively to modern ears) "God does exist" (Hobbes 1656, 228; More 1662, 22). ${ }^{15}$ Such axioms were often left implicit, precisely because their truth was beyond dispute, although they were more likely to be made explicit in deductive contexts. Newton used axioms in this way in the Opticks. The Opticks's axioms include claims like "The angle of Reflexion is equal to the Angle of Incidence" and "An Objects seen by Reflexion or Refraction, appears in that place from whence the Rays after their last Reflextion or Refraction diverge in falling on the Spectator's Eye" $(5,18)$. Immediately after them, Newton notes: "I have now given in Axioms and their Explications the sum of what hath hitherto been treated of in Opticks. For what hath been generally agreed on I content my self to assume under the notion of Principles..." (Newton 1952, 19-20, emphasis added). We believe Newton uses "axioms" in the Principia in the same way. In fact, the second Liber Primus - the first extant work where "axioms" are used - is also the first extant work that contains the already discussed appeal Wren, Wallis, and Huygens, as well as the extended discussion that justifies the laws (particularly the third) with a wide range of examples from the domain of simple machines and collision theory. ${ }^{16}$ In other words, "axioms" were likely introduced by Newton as he was making an even more extended case for the connection between his principles and the entirety of mechanical practice before him.

To sum up, we claim that Newton turns to 'laws of motion' and then 'axioms or laws of motion' from 'hypotheses' for three main reason: 1) he gains confidence that they provide a means of distinguishing true and apparent motions, and thus capture fundamental features of reality; 2) that they are not only applicable to celestial motion, but to the analysis of traditional mechanical problems and collisions; and 3) that they have been presupposed by his predecessors' treatment of mechanical problems and collisions, even if not formulated as clearly. This is not to say that these were Newton's only motivations for the terminological change. For example, in the preface to the Principia, Newton is clearly concerned to defend the status of his mechanics as properly mathematical, and there is good reason to believe that his use of 'axioms' is meant to recruit the term's mathematical connotations. ${ }^{17}$ Still, Newton's introduction of "laws" and "axioms" predate his explicit concern with his work's mathematical status. In fact, we've argued that the timing of the terms' introduction coincides with Newton's articulation of a different set of concerns, ones concerning the truth of and broad agreement regarding his principles. ${ }^{18} \mathrm{~A}$ reader may well wonder how the use of 'laws' connects to Newton's theology. After all it is often thought that laws presuppose a lawgiver. In order to get clear on this issue, we now turn to Newton's treatment of the metaphysics and modality of laws.

\footnotetext{
${ }^{14}$ While it is possible that Newton added the label "Axiomata" to "Leges Motus" in the first Liber Primus, the term is missing from Halley's commentary on the work (Cohen 1971, 336-344).

${ }^{15}$ In the Lexicon Technicum of 1708, John Harris wrote: "AXIOM, is such a common, plain, self evident, and received Notion, that it cannot be made more plain and evident by Demonstration..."

${ }^{16}$ Newton singles out the third law, noting that he wished to show "the wide range and the certainty of the third law of motion." (Newton 1999: 430)

${ }^{17}$ We thank an anonymous referee for urging us to stress this point. See also Gabbey (1992) and Bertoloni Meli (2010).

${ }^{18}$ These decisions reflect only one attitude towards 'laws,' from the various possible in the late seventeenth century. For a thorough discussion of the concerns embodied in the debates about 'laws,' see Steinle (2002) and Ott (2009).
} 


\section{The Modality and Grounding of Newton's Laws, and Contemporary Accounts}

While Newton's confidence in the truth of his laws is clear, his position on their metaphysics is harder to determine. There are only a few key passages in his corpus that address the topic directly. The most significant was introduced in the 1706 Latin edition of the Opticks and ultimately ended up in Query 31 of the later English edition. We focus on it because Newton published it under his own name. It reads:

Since Space is Divisible in infinitum, and Matter is not necessarily in all places, it may also be allowed that God is able to create Particles of Matter of several Sizes and Figures, and in several Proportions to Space, and perhaps of different Densities and Forces, and thereby to vary the Laws of Nature, and make Worlds of several sorts in several Parts of the Universe. (Newton 1952, 403-404)

In the Principia itself, Newton did not offer a definitive, or even speculative, cosmogony. In the first edition (1687), he made the (Epicurean) suggestion that comets bring seeds of life from one solar system to another, and intimated that nature is cyclical, with its cycles instituted by a providential, but not especially Christian God. In the second edition (1713), he appealed to a more heterodox Christian theology (in the General Scholium), and argued that a Designer-God must be posited in order to explain the stability of celestial orbits (Schliesser 2013b). The Opticks passage above provides more detail on this cosmogony.

A terminological point is in order. Newton sometimes uses 'world' in a metaphysically neutral sense, to mean a solar system or, more generally, a closed (or virtually closed) system of interacting celestial bodies. ${ }^{19}$ In the above passage, however, 'world' is a metaphysically richer notion. A world in this sense is constituted by the kinds of particles and forces it contains, particles and forces that are ontologically prior to the world they constitute. Moreover, the above passage suggests that within 'worlds' of this kind particles and forces are prior, in some sense, to the laws of nature.

We will return to issue of priority shortly. First, however, note that for Newton laws are clearly contingent. They are not grounded in God's immutability (as Descartes's were), but depend on God's arbitrary will. Their contingency stands in stark contrast to the necessity of Newtonian space and time. For Newton, space and time could not have been otherwise and are a consequence of God's necessary existence. As he writes in the General Scholium, "by existing always and every where, [God] constitutes Duration and Space...'Tis allowed by all that the supreme God exists necessarily; and by the same necessity he exists always and every where" (Principia, 942). ${ }^{20}$ Physical laws do not possess such necessity. ${ }^{21}$ As Roger Cotes wrote in the

\footnotetext{
${ }^{19}$ In the scholium to the definitions of the Principia, Newton shows that in order for the First Law to hold for the center of mass of a closed system of interacting bodies, the Third Law must hold for the interactions among the bodies. In addition, in Corollary 5 to the Laws he makes it clear that the relative motions of a closed system of bodies are not affected if the entire system moves uniformly without rotation (for details see Smeenk \& Schliesser 2013).

20 There has been a tendency to ignore Newton's commitment to God's necessary existence by both those that tend to read Newton as a thoroughgoing empiricist (e.g., Stein 2002, Di Salle 2002) and those that tend to emphasize inductive, design arguments when discussing Newton's theology (Hurllbutt 1965). For a useful, Kantian corrective to this tendency see Janiak 2008.

${ }^{21}$ In the General Scholium Newton deploys a principle that if some effect $\mathrm{Y}$ is universal temporally and spatially, then we can infer or posit as the ultimate cause something that itself is necessary in a way that accounts for Y (this is
} 
editor's preface to the second edition: "From this source [God], then, have all the laws that are called laws of nature come, in which many traces of the highest wisdom and counsel certainly appear, but no traces of necessity." (Principia, 397) ${ }^{22}$

In the above passage, the contingency of Newton's laws is also coupled to the claim that they are not universal. They may hold of some worlds (in the metaphysical sense), but not all. Their variability has at least two consequences. First, a universe with metaphysically distinct worlds entails causal disconnectedness among (some of) its parts. ${ }^{23}$ This disconnectedness appealed to Newton, because it could prevent different solar systems from collapsing in on each other. It thus supports the argument from design of the General Scholium (Principia, 940).

Second, the variability of laws raises a possible (but ultimately only apparent) conflict with Newton's third rule of reasoning. The rule reads, "Those qualities of bodies that cannot be intended and remitted and that belong to all bodies on which experiments can be made should be taken as qualities of all bodies universally" (Principia, 795). Newton's position relies (as his long commentary on the third rule shows) on a distinction between universal and essential qualities (Schliesser 2011a). The latter are necessary for a thing to be the kind of thing it is, while the former are metaphysically optional. The third rule states that universal qualities, despite their inessentiality, are present in every bit of matter, whether in our region or elsewhere. The tension between this universality and the variability endorsed in the Opticks passage can be put thus: the third rule recommends that certain features of the physical world ought to be taken as universal, while the Opticks passage suggests that such features may vary from region to region.

However, the tension can be resolved by taking the third rule as a claim about how qualities should be taken in the context of natural philosophical research, as distinct from the context of speculative cosmogony. ${ }^{24}$ The third rule offers a bold generalization from what is empirically available to domains beyond our experimental grasp, both from the visible to the microscopic (so-called 'transduction'; see McGuire 1970 and Belkind 2012) and from this world to other worlds. George Smith (2014) has explained the epistemic pay-off of such boldness in light of Newton's subtle methodology. His account relies on Newton's fourth rule of reasoning, which state that

In experimental philosophy, propositions gathered from phenomena by induction should be considered either exactly or very nearly true notwithstanding any contrary hypotheses, until yet other phenomena make such propositions either more exact or liable to exceptions. This rule should be followed so that arguments based on induction may not be nullified by hypotheses. (Principia, 796)

\footnotetext{
one of the arguments for God's necessary existence and the principle is also used in a criticism of Spinozism that need not concern us here). For more on this see Schliesser "Newton's Polemics with Spinozism" (under review). Furthermore, we should make clear that although Newton's laws are contingent, they are necessary in relation to God's will. Given God's edicts, they could not be otherwise. See Massimi (2014). We thank Michela Massimi for stressing this to us.

22 The denial of necessity distances Newton from the charge of Spinozism and its attack on design arguments.

23 At the end of the vortex theory promoted in his posthumous Cosmotheoros (1698), Huygens explicitly posits causal disconnectedness between solar systems, which entails a denial of a universe wide vortex. We thank Chris Smeenk for calling our attention to this.

${ }^{24}$ That is, "universally" means something akin to (adopt Leibnizian terminology) "for all particles (in the actual world)" and not "for all particles (in all possible worlds)." For Newton, of course, those "possible worlds' may obtain in our own universe. We thank Michela Massimi for discussion.
} 
According to Smith, the fourth rule teaches us that the pay-off to inductive boldness is the ability to find phenomena that make induced propositions better qualified, either by making those propositions more and more accurate, or by revealing that they only hold accurately in limited domains or under restricted conditions.

The rules' emphasis on the epistemic attitude to be taken in the context of natural philosophical research suggests that Newton's position on the variability of laws is compatible both with (a) the universe having more than one kind of law of nature, each holding for a different world (or system of worlds) and (b) the universe having one set of laws of nature that cover all the systems of worlds, as long as only (b) is held as an effective position in the context of natural philosophical inquiry. Newton recognizes that the empirical support for his laws is strong, but limited. Consequently, when he reflects more speculatively on ontology, he can allow something like (a). But when writing for methodological purposes, (and in the context of natural philosophical inquiry), he adopts (b) as the engine of future research. Put differently, within the context of research, Newton advocates taking as true (in accordance with the fourth rule) the idea that the universe has one set of laws that cover all the systems of worlds; and that within that context the possibility of (a) cannot be used to nullify (say) the universal character of gravity. But Newton allows that, in a different register, one can speculate about alternative possibilities that may turn out to be fruitful in the future. The possibility of multiple laws thus may become live if empirical inquiry were to encompass areas of the universe God has populated with particles and forces different from our own. And so, although the laws are deeply entrenched in inquiry, exceptions to them are not only methodologically significant, but may eventually reveal that we need to restrict the laws' scope.

There is also another, harder to reconcile tension in Newton's account of laws. In the passage above, he suggests that particles and forces are ontologically prior, and that laws are dependent on them: "it may also be allowed that God is able to create Particles ... and forces... and thereby [eoque; pacto] to vary the Laws of Nature" (emphasis added). ${ }^{25}$ There are similar statements elsewhere in the Opticks, e.g.,: "[particles have] a vis inertiae, accompanied with such passive laws of motion as naturally result from that force..." (Newton 1952, 401, emphasis added). However, the notion of dependence is left unspecified. Moreover, Newton also suggests the opposite. In De Gravitatione (an early text, written before the discovery of universal gravitation), he speculates that "If we should suppose that... impenetrability is not always maintained in the same part of space but can be transferred here and there according to certain laws, ... there will be no property of body which it does not possess." (Newton 2004, 28, emphasis added). This earlier text suggests that the force of impenetrability and the laws of nature are fundamental, and these give rise to all other features of body-including the forces studied elsewhere in De Grav - and the higher-order laws that govern them. Even later in life, Newton suggests the same. In the Opticks, Newton highlights the difference between his philosophy and its competitors: "These principles I consider, not as occult qualities, supposed to result from the specific forms of things, but as general laws of nature, by which the things themselves are formed..." (Newton 1952, 401). It might be tempting to think that only nonuniversal features of body might result from the laws of nature, since Newton's target here is

\footnotetext{
${ }^{25}$ The passage first appeared in Latin: "illud insuper concedi necesse est, uniq, posse Deum creare..., vario quoque; numero \& quantitate pro ratione Spatii in quo insunt, forte etiam \& diversis densitatibus diversisq, viribus, eoq, pacto variare Leges Naturae, mondosq; condere diversa Specie, in diversis Spatii universi particus." (Newton 1706, 347). In English, "eoq, pacto" was rendered as "thereby," but it has rather strong causal connotations, and can also be rendered as "in that manner," or replicating the latin most closely, "thereby, in that manner."
} 
specific forms (i.e., the form of water, wood, and gold). However, the context of the passage suggests otherwise. We quote more fully:

It seems to me farther, that these Particles have not only a Vis inertia, accompanied with such passive Laws of Motion as naturally result from that Force, but also that they are moved by certain active Principles, such as is that of Gravity, and that which causes Fermentation, and the Cohesion of Bodies. These Principles I consider, not as occult Qualities, supposed to result from the specifick Forms of Things, but as general Laws of Nature, by which the Things themselves are form'd (Newton 1952, 401, emphasis added).

We read the passage as asserting that in Newtonian philosophy, active principles-even universal ones like gravity - just are general laws of nature, and those laws form the things, which they govern. Of course, there are other ways to read the passage. However, our point is that those are available because there is an inherent tension in Newton's account, one which we can now state explicitly: in certain passages, Newton asserts that laws are expressions of the natures of the entities they govern, and in other passages, he asserts that the natures of various entities (including forces) arise from the laws that govern them.

As far as we know, Newton does not address this tension directly or provide means for solving it. The available evidence suggests that he saw his position as entirely coherent. And although it may not seem so from a contemporary perspective, it fits well with a form of causation Newton endorsed in other contexts: formal causation.

For, as David Hume correctly discerned, for Newton laws are genuine, so-called secondary causes. ${ }^{26}$ However, they are not efficient. They akin to formal causes in a traditional, Scholastic sense (Kuhn 1977, 21-30). In one sense, a formal cause constitutes (and is thus prior) to the substance in which it inheres. Without a formal cause, a substance would not be what it is and or do what it does. In another sense, a substance is prior to its form. Substance is the genuine existent and subject of predication, and form's existence is grounded in the existence of substance. It is thus possible to speak both of forms as forming substances and as substances as grounding forms. This tension-which is built directly into the notion of formal causationmirrors the tension in Newton's account of laws. In one sense, bodies and forces are prior to the laws of nature, since from different forces and bodies arise different laws of nature. In another sense, laws of nature are prior to bodies and forces, since they are the principles by which the "things themselves" are formed (see also Schliesser 2013a, McGuire 2007).

The second tension in Newton' account eliminates several other interpretations of his understanding of 'laws.' To begin with, it is clear that Newton is not a Humean avant la letter; he does not think of laws as supervening on states of affairs. Moreover, he is not a straightforward power-theorist. Laws do not (merely) arise for him from underlying powers and capacities, but are constitutive of the forms that delimit those powers and capacities.

The tension also places Newton in an unusual, hybrid position vis-à-vis contemporary accounts of laws. Its proto-Kantianism is best brought out through comparison with Katherine Brading's account. Brading $(2011,2012)$ has argued that Newton's laws are partially constitutive of Newtonian metaphysics, particularly his account of body. To ask what body is, according to her, is to ask what the laws say about bodies. Thus, for Newton, the metaphysics of body is turned into a part of empirical inquiry: in order to determine what bodies are, determine what the

\footnotetext{
${ }^{26}$ David Hume EHU 7.25 n. 16, http://davidhume.org/texts/ehu.html\#Ea16. In early modern terminology God is the first cause, and secondary causes are other causes in the world (for careful treatment, see Hattab 2000).
} 
laws of nature are. In subsequent work, Brading has explained how the reception of Newton's Principia and eighteenth-century developments in physics can be understood as an unfolding of such metaphysics. Brading's account dovetails nicely with the conception of laws as formal causes: they (at least partially) define what bodies are and how they behave. And although Brading eschews causal language in her law-constitutive account, ${ }^{27}$ this sort of constitution was often understood (before Kant) as formal causation (as Kuhn noted in 1977, 21-30). It is for this reasons that we call laws the 'formal' causes of bodies and forces, thereby also picking out something resembling Baconian forms (Schliesser 2013a). We are not suggesting that Brading is Kantian. Rather, we are suggesting that Brading's account is useful for understanding Newton's allegiance to the law-constitution central to Kantian accounts.

DiSalle (2002; 2006) offers such a Kantian account. He argues for the constitutive character of Newton's laws by showing that the fundamental concepts of Newton's system are required in order to give empirical meaning to the laws. For example, he holds that to find the meaning of absolute time and motion, we must ask how such concepts can be interpreted in a way that makes possible physical inquiry guided by the laws. DiSalle's case is compelling, however, we do not think that Kantian accounts like his do full justice to Newton's position. The crux of the issue is that Newton's accounts of body and the laws are embedded in a set of broader ontological commitments, which Kantian approaches (and Brading's law-constitutive approach) do not adequately represent. It is true that Newton's approach to natural philosophy opened the door for a more thoroughgoing law-constitutive approach to metaphysics. But that approach was not yet wholly in place for Newton himself. We can see this in two ways.

First, Brading and DiSalle's positions underdetermine the (unusual) modal status ascribed by Newton to the laws. The laws really could have been otherwise in our region of the universe and, for all we know, may be otherwise in other regions. That is (recall), they are true of all the known systems of bodies of the actual world and not for all the systems of bodies in all possible worlds within our universe (see also Miller 2009). How are we to describe their modality on accounts that stress their constitutive character? Since laws become the guides to metaphysics on such accounts, questions regarding their own modality become difficult to answer.

The same holds of accounts that take laws as primitives, e.g., Maudlin's. Maudlin (2007) treats laws as our ultimate guides to physical necessity and possibility. This may very well be the case, of course, but it is not the way Newton treated his laws. For Newton, while the laws are epistemically useful guides to discovering physical possibility within our world (in his metaphysically rich sense), they are neither primitive tout court nor do they constitute metaphysical possibility. The laws could have been otherwise, and they could have been otherwise because they are dependent on - in the way in which formal causes are dependent on their bearers - the particles and forces God chose to create. Thus, laws are crucial to Newton's epistemology, as commentators have rightly noted, but not to his metaphysics nor his views on modality. This connects to our second concern.

Second, accounts that stress the constitutive character of Newton's laws do not do full justice to the fact that Newton explicitly claims that the laws are grounded in (contingent) bodies and forces. As we saw, in the Opticks the laws arise from God's creation of particular sorts of

\footnotetext{
${ }^{27}$ Brading does so for principled reasons. Her account relies on the conception of laws inherent in the Principia, and that conception leaves much (intentionally) unspecified. Our account here relies on Newton's more speculative statements in the Opticks. Although the overall significance of the "Queries" is a subject too detailed to address here, we take them to indicate Newton's deeply held beliefs, albeit ones that he could not sufficiently support on empirical grounds.
} 
matter and force. Constitutive approaches represent the deep connection between bodies and laws, but emphasize only half of the picture. Newton believes both that laws constitute bodies and forces ("from which the things themselves are form'd") and that laws are grounded in the kinds of bodies and forces that exist ("as naturally arise from" them). The two halves of the picture are compatible (if we keep formal causality in mind), but many of Newton's metaphysical commitments simply disappear if we only keep the former in mind. Newton is more of a neo-Aristotelian about the metaphysics of laws. When God creates, he creates bodies with properties. What those bodies are is given by laws, but the laws have no existence apart from their grounding in those bodies. ${ }^{28}$

\section{Conclusion}

In conclusion, we have argued that by using 'Axioms, that is, laws of motion,' Newton signals that he is developing his account from shared premises found in the successful development of seventeenth century mechanics (e.g., as it culminates in Huygens's work). Newton's trust in their certainty (as described in Rules 3 and 4 of the Regulae Philosophandi) arises from their shared status, as well as Newton's growing confidence that they latch on to fundamental features of reality. This dual use of 'axioms' and 'laws' was not entirely novel in Newton's time. Even so, Newton's position is a striking rejection of the position endorsed by many mechanical philosophers, such as Huygens. The Principia does not offer mere mathematical models that provide an intelligible explanation of the phenomena. Rather, its laws characterize the exact and true relations of features of reality, in the spirit of fallibilism. Newton's confidence in the truths of his laws gives rise to two tensions. The first arises from the juxtaposition of his confidence in their truth and his commitment to their variability and contingency. We have argued that this tension is resolvable, since Newton's statements about variability and contingency are set in a metaphysical, speculative register, while his statements about certainty and fallibility are set in a more cautious register, one appropriate for natural inquiry. The second tension arises from Newton various statements about the grounding and fundamentality of the laws of nature: he ascribes fundamental status to both the laws of nature and to the bodies and forces, which they govern. We have argued that this tension is not resolvable, but that it is inherent in a neoAristotelian conception of formal causation. Laws, we have suggested, are formal causes of bodies and forces in Newton's universe. Their existence is grounded in the existence of certain types of bodies and forces, but the natures of those bodies and forces are grounded in God's choice of laws. We have related this conception to two contemporary accounts of laws, highlighting in particular their relation to Kantian-inspired conceptions.

\section{Acknowledgements}

We thank the editors of this volume for their incisive comments. In addition, we are grateful to Andreas Hüttemann, Ruth Groff, Barry Loewer, and, especially, Katherine Brading, for extremely helpful comments. The usual caveats apply.

\section{References}

\footnotetext{
${ }^{28}$ Whether passive bodies can count as 'substances' for Newton is a separate question, see Schliesser 2011c.
} 
Belkind, Ori 2012. "Newton's Scientific Method and the Universal Law of Gravitation," in A. Janiak and E. Schliesser, eds. (2012, 138-168).

Bertoloni Meli, Domenico. Thinking with objects: The transformation of mechanics in the seventeenth century. Johns Hopkins University Press, 2006.

Bertoloni Meli, Domenico. "The axiomatic tradition in seventeenth-century mechanics." Discourse on a New Method: Reinvigorating the Marriage of History and Philosophy of Science (2010): 21 .

Biener, Zvi, forthcoming-a. "De Gravitatione Reconsidered: The Changing Role of Geometrical Definitions in Newton's Metaphysics of Space," Journal of the History of Philosophy.

Biener, Zvi and Eric Schliesser, eds. 2014. Newton and Empiricism, Oxford: Oxford University Press.

Bitbol, Michel, Pierre Kerszberg and Jean Petitot, eds. 2009. Constituting Objectivity Transcendental Perspectives on Modern Physics, Springer Verlag.

Brading, Katherine 2011. "On composite systems: Descartes, Newton, and the Law-Constitutive Approach," in D. Jalobeanu and P.R. Anstey (2011, 130-152).

Brading, Katherine 2012. "Newton's Law-Constitutive Approach to Bodies: A Response to Descartes," in A. Janiak and E. Schliesser, eds. (2012, 13-32).

Buchwald, Mordechai and Fox, Robert, eds. 2013. The Oxford Handbook of the History of Physics, Oxford: Oxford University Press.

Cohen, I. Bernard 1971. Introduction to Newton's Principia, Harvard: Harvard University Press.

Cohen, I. Bernard, and George E. Smith, eds. 2002. The Cambridge Companion to Newton, Cambridge: Cambridge University Press.

Detel, Wolfgang and Zittel, Claus, eds. 2002. Ideals and Cultures of Knowledge in Early Modem Europe. Frankfurt: Akademie Verlag.

DiSalle, Robert 2002. "Newton's philosophical analysis of space and time," in I. B. Cohen and G. E. Smith, eds. (2002, 33-56).

DiSalle, Robert 2006. Understanding Space-Time: The Philosophical Development of Physics from Newton to Einstein. Cambridge: Cambridge University Press.

Friedman, Michael 2001. Dynamics of Reason, Stanford: CSLI Publications.

Friedman, Michael 2009. "Newton and Kant on Absolute Space: From Theology to Transcendental Philosophy," in M. Bitbol, P. Kreszberg and J. Petitot (2009, 35-50). 
Gabbey, Alan 1992. "Newton's Mathematical principles of natural philosophy: A treatise on 'Mechanics'." In Harman, P. M. and Shapiro, A. E., eds. The Investigation of Difficult Things. Cambridge: Cambridge University Press, 305-322.

Garber, Daniel 2000. “A Different Descartes: Descartes and the Programme for a Mathematical Physics in His Correspondence," in S. Gaukroger, J. Schuster and J. Sutton, eds. (2000, 113130).

Gaukroger, Stephen, John Schuster and John Sutton, eds. 2000. Descartes' Natural Philosophy, New York: Routledge.

Hall, A. Rupert 1952. Ballistics in the Seventeenth Century, Cambridge University Press, Cambridge.

Harris, John 1708. Lexicon Technicum. $2^{\text {nd }}$ Edition. London.

Hattab, Helen 2000. "The Problem of Secondary Causation in Descartes: A Response to Des Chene," Perspectives on Science 8(2): 93-118.

Herivel, John 1965. The Background to Newton's Principia, Oxford: Oxford University Press.

Hobbes, Thomas 1656. Six Lessons to the Professors... in the University of Oxford, London: Andrew Cook.

Hume, David 2000-2016. Davidhume.org Edited by Peter Millican and Amyas Merivale,

Hurlbutt, R. H. 1965. Hume, Newton, and the Design Argument. Lincoln: University of Nebraska Press.

Huygens, Christiaan 1690. Traité de la Lumière (Treatise on Light), in The Scientifc Background to Modern Philosophy, ed. and trans. M. Matthews, Indianapolis and Cambridge. Mass.: Hackett, 124-32.

Jalobeanu, Dana 2011. "The Cartesians of the Royal Society: The Debate over Collisions and the Nature of Body (1668-1670)," in D. Jalobeanu and P. R. Anstey, eds. (2011, 103-129).

Jalobeanu, Dana and Peter R. Anstey, eds. 2011. Vanishing Matter and the Laws of Motion: Descartes and Beyond, New York: Routledge.

Janiak, Andrew 2008. Newton as Philosopher, Cambridge: Cambridge University Press.

Janiak, Andrew and Eric Schliesser, eds. 2012. Interpreting Newton: Critical Essays, Cambridge: Cambridge University Press.

Kochiras, Hylarie 2013. "The Mechanical Philosophy and Newton's Mechanical Force." Philosophy of Science 80 (4): 557-578. 
Kuhn, Thomas 1977. The essential tension: Selected studies in scientific tradition and change, Chicago: University of Chicago Press.

Maudlin, Tim 2007. The Metaphysics within Physics, Oxford: Oxford University Press.

Massimi, Michela 2014. "Prescribing Laws to Nature. Part I. Newton, the pre-Critical Kant, and Three Problems about the Lawfulness of Nature," Kant-Studien 105 (4): 491-508.

McGuire, J. E. 1970. "Atoms and the 'Analogy of Nature': Newton's Third Rule of Philosophizing," Studies in History and Philosophy of Science 1(1) : 3-58.

McGuire, J. E. 2007. “A Dialogue with Descartes: Newton's Ontology of True and Immutable Natures," Journal of the History of Philosophy 45(1): 103-125.

Miller, David Marshall. "Qualities, properties, and laws in Newton's induction." Philosophy of Science 76.5 (2009): 1052-1063.

More, Thomas 1662. An Antidote Against Atheism, third edition, London: James Fletcher.

Newton, Isaac 1706. Optice: Sive De Reflexionibus, Refractionibus, Inflexionibus \& Coloribus Lucis. Libri Tres. London.

Newton, Isaac 1989. The Preliminary Manuscripts for Isaac Newton's 1687 Principia, 16841685. Cambridge University Press, Cambridge.

Newton, Isaac 1999. The Principia: Mathematical Principles of Natural Philosophy, trans. I. B. Cohen and A. M. Whitman, Berkeley: University of California Press.

Ott, Walter 2009. Causation and Laws of Nature in Early Modern Philosophy, Oxford: Oxford University Press.

Schliesser, Eric 2011a. "Without God: Gravity as a Relational Quality of Matter in Newton's Treatise, “ in D. Jalobeanu and P. R. Anstey, eds. (2011, 80-102).

Schliesser, Eric 2011b. "Newton's Challenge to Philosophy: A Programmatic Essay," HOPOS: The Journal of the International Society for the History of Philosophy of Science 1 (1): 101-128.

Schliesser, Eric. 2011c. 'Newton's substance monism, distant action, and the nature of Newton's empiricism: discussion of H. Kochiras "Gravity and Newton's substance counting problem,"' Studies in History and Philosophy of Science Part A 42 (1): 160-166.

Schliesser, Eric 2013a. "Newtonian Emanation, Spinozism, Measurement and the Baconian Origins of the Laws of Nature," Foundations of Science 18 (3): 449-466. 
Schliesser, Eric 2013b. "On Reading Newton as an Epicurean: Kant, Spinozism and the Changes to the Principia," Studies in History and Philosophy of Science Part A 44 (3): 416-428.

Shapiro, Alan 1989. "Huygens' Traité de la Lumière and Newton's Opticks': Pursuing and eschewing Hypotheses," Notes and Records of the Royal Society, 43: 223-47.

Smeenk, Christopher, and Eric Schliesser 2013. "Newton's principia," in Buchwald and Fox, eds. (2013, 109-165).

Smeenk, Chris and George E. Smith (mss). "Newton on Constrained Motion."

Smith, G. E. 2002. "The Methodology of the Principia," in Cohen and Smith, eds. (2002, 138173).

Smith, George E. 2008. "Isaac Newton," The Stanford Encyclopedia of Philosophy (Fall 2008 Edition), Edward N. Zalta, ed. URL $<$ http://plato.stanford.edu/archives/fall2008/entries/newton/>.

Smith, George E. "Closing the Loop: Testing Newtonian Gravity, then and Now," in Biener and Schliesser, eds. (2014, 262-351).

Stein, Howard 1990. "From the Phenomena of Motions to the Forces of Nature': Hypothesis or Deduction?," PSA: Proceedings of the Biennial Meeting of the Philosophy of Science Association, Philosophy of Science Association.

Stein, Howard 2002. "Newton's Metaphysics," in Cohen and Smith, eds. (2002, 256-307).

Steinle, Friedrich 2002. "Negotiating Experiment, Reason, and Theology: The Concept of Laws of Nature in the Early Royal Society," in Detel and Zittel (2002, 197-212). 